\title{
frontiers
}

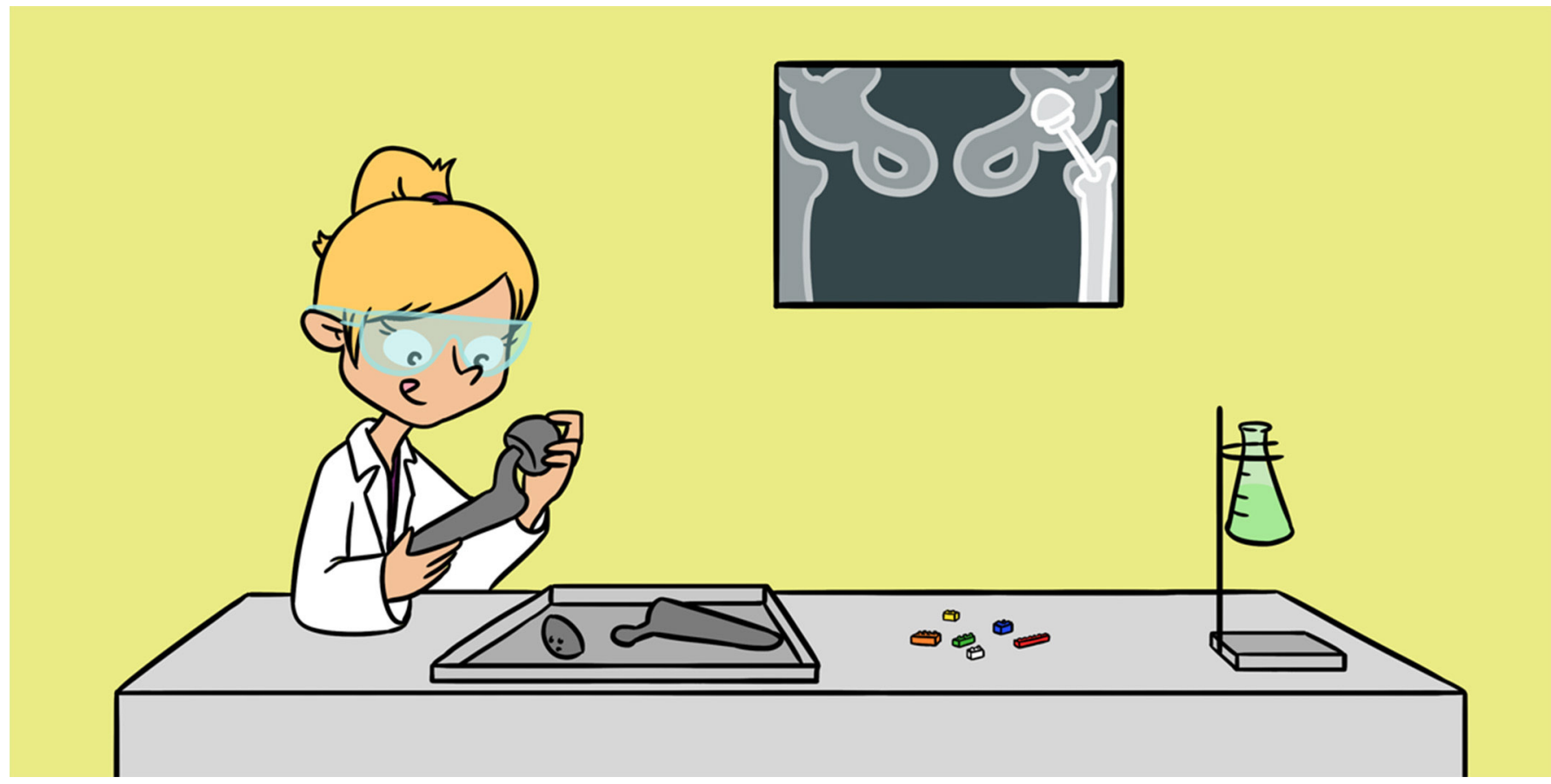

\section{BIOMATERIALS FOR ORGAN AND TISSUE REPAIR}

\section{Caitlin Lazurko ${ }^{1,2}$, Serena Harden ${ }^{1}$,Erik J. Suuronen ${ }^{1,3 *}$ and Emilio I. Alarcon ${ }^{1,2 *}$ \\ Division of Cardiac Surgery, University of Ottawa Heart Institute, Ottawa, ON, Canada \\ 2 Department of Biochemistry, Microbiology, and Immunology, Faculty of Medicine, University of Ottawa, Ottawa, ON, Canada \\ ${ }^{3}$ Department of Cellular and Molecular Medicine, Faculty of Medicine, University of Ottawa, Ottawa, ON, Canada}

\section{YOUNG REVIEWER:} CAROLINE AGE: 15
Organs and tissues in the human body are quite resilient to the wear and tear of daily human life, but they can still fail for many reasons. Regenerative medicine is a field that explores new tools for repairing and replacing damaged organs and tissues. Regenerative medicine includes a vast array of treatments; for example, stem cell therapy, and biomaterials. Biomaterials are materials made to interact with the human body. They can be designed with many different materials for different applications and can be made structurally similar to the organ or tissue that needs to be repaired. The field of biomaterials is constantly evolving and as we continue to learn more about the interactions of biomaterials with the body on a cellular level, more and more biomaterial treatments are being developed. 


\section{BIOMATERIALS: BUILDING BLOCKS FOR TISSUE REPAIR}

Organs and tissues in the human body have very specific, complicated functions. Our lives depend on these organs to function correctly and around the clock. However, sometimes organs and tissues are damaged and can fail, due to illnesses or accidents. There are many medical therapies that can help treat damaged organs, but many still lack the ability to repair the organ so that it regains full function. For example, current treatments do not really improve heart function after a heart attack.

Regenerative medicine is a field of research that provides new tools for repairing failing organs and replacing damaged tissues [1]. Regenerative medicine uses something called tissue engineering to design new strategies for repair of damaged organs and tissue. Tissue engineering means using biology, chemistry, and engineering to make new materials that are compatible with the human body and can be used to fix or replace organs and tissues [2]. There are a wide range of therapies included in the field of regenerative medicine, with biomaterials being one of the more commonly used tools. Biomaterials are like Lego ${ }^{\circledR}$ building blocks, and have been used to repair tissues and organs, such as the heart, skin, cornea, and nervous system [3]. Biomaterials are materials meant to be inserted into the body to replace or repair damaged organs or tissues. Biomaterials often have special properties that allow them to be in contact with human cells, tissue, and organs without being rejected by the body. Bioengineering is the name of the field that creates and uses biomaterials to improve current medical treatments $[2,3]$.

Regenerative medicine also uses a variety of ways to apply its therapies so they can work effectively. Regenerative therapies can include: (1) cell therapy using stem cells, which are immature cells that can potentially become or produce any cell or tissue necessary, (2) bioengineering using biomaterials, as we have described here, and (3) medications and drug treatments $[1,3]$. As regenerative medicine changes, the ways the treatments are applied is also changing, often by combining existing methods or making new ones that are more suitable for the treatment. Biomaterials, bioengineering, and regenerative medicine are currently leading the way for new medical therapies, especially for repairing organs that have previously thought to be unrepairable.

\section{THE STORY OF BIOMATERIALS}

Biomaterials have improved significantly since they were first developed, and they are still changing, as scientists continue to understand 
REGENERATION

Re-grow.

\section{POROUS}

Small holes to allow air, liquids, and even cells to pass through. more about diseases and how the biomaterials interact with the body [3]. Biomaterials can be created from a variety of materials, depending on what they will be used for [2,3]. For example, they can be made from various types of natural components, such as collagen which is found in the body or alginate which comes from seaweed, synthetic materials, such as metal, or a combination [2, 3]. The earliest biomaterials did not interact with the human body, but they had similar physical properties to the damaged organs they were being used to repair or replace. These materials were often created from various metals, ceramics, or substances, such as rubber. These early biomaterials were commonly used as prosthetics, which are artificial body parts such as a leg or a heart, but they had poor combability with the body so they would often be rejected. These early materials could not interact with the body on a cellular level, which is what today's biomaterials aim to do. Advances in the development of novel biomaterials have led materials that can interact with the body to promote healing and regeneration. These newer biomaterials were considered bioactive, meaning they could interact with the body, and form chemical bonds with tissues. This is seen in hip implants that promote bone growth which allow a calcium layer, called hydroxyapatite, to grow on the implant. The newest biomaterials, known as third generation biomaterials, are made to interact with the body and cause a specific response from cells in the body. Third generation biomaterials can also mimic the body's natural 3D structure and stimulate tissue regeneration (re-growth) [3]. Scientists have improved biomaterials tremendously and they continue to work on them, changing the materials' properties to operate more effectively in patients' bodies.

\section{WHAT SHAPE DO BIOMATERIALS TAKE?}

Biomaterials can take on many different forms and be made from many different materials. Ideally, biomaterials should have a porous structure, which means they have small holes which lets gasses, liquids, and even cells move through them, similar to the organ or tissue they aim to heal. Cells that help in healing can also be loaded into the small pores in the biomaterial [2]. In this way, a porous biomaterial can be used to deliver cells to a damaged tissue. The biomaterial helps keep the new cells in the tissue where they are needed to promote healing. Additionally, the porous structure of the biomaterial is a lot like the "extracellular matrix," which is like the scaffolding that cells "hold on to" in the body $[2,3]$. Biomaterials can either be used by themselves as a treatment, or, like the example above, they can be modified to contain medicine or cells to help repair damaged tissues (Figure 1). For example, biomaterials can be used to help heal and repair the heart after a heart attack. 
Figure 1

Biomaterials for tissue and organ repair. Biomaterials can contain cells (top) or be used by themselves in the patient (bottom). After some healing time, both types of biomaterials could help the damaged tissue regain its healthy functions and properties.

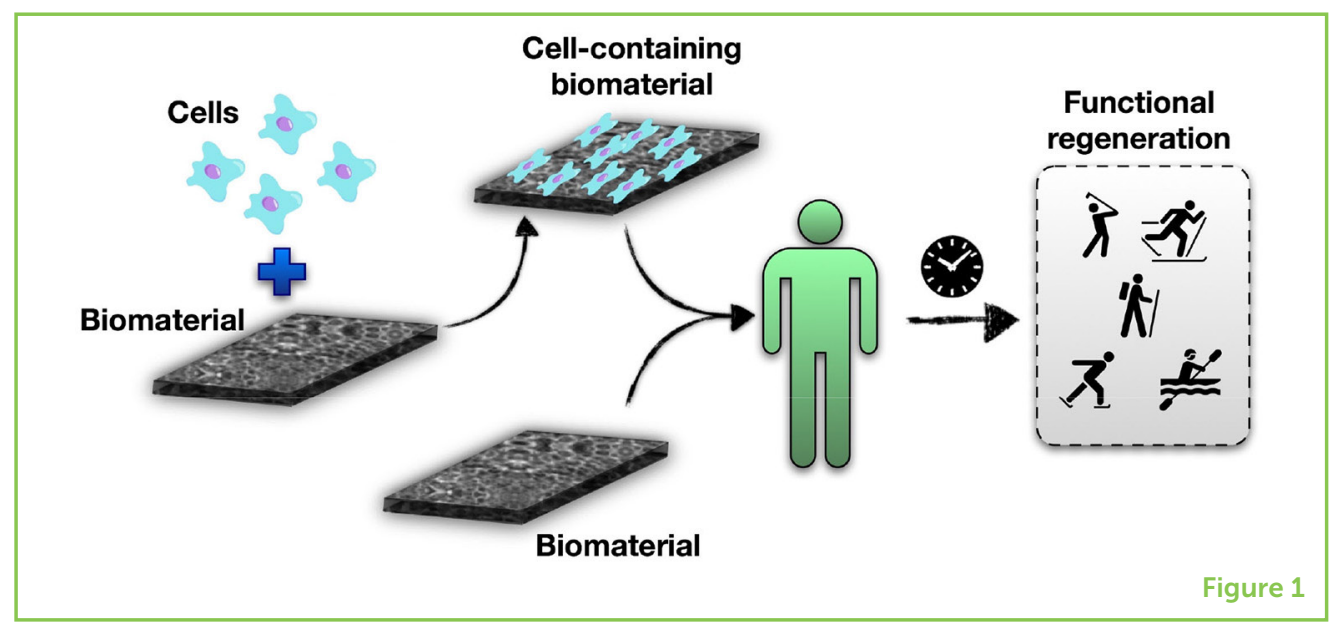

They can be used alone, or they can contain stem cells, which are cells that have the ability to become different types of cells, including heart cells. Some biomaterials can be prepared to break down after healing has finished $[2,3]$. Biomaterials can also be made to release certain medications that can help in the healing process $[1,3]$. Future developments in biomaterials could lead to the production of many new therapies, including artificial organs. This would eliminate the long waiting list for organ transplants.

\section{BIOMATERIALS CAN HELP HEAL NON-HEALING ORGANS}

Organs fail for many different reasons, often due to a combination of factors. The heart is one of the most common organs to fail, and one of the most difficult to heal. Cardiovascular disease (CVD) is a term used for illnesses that affect the heart and blood vessels. Patients with CVD are at risk of having heart attacks, which can cause significant damage to the heart and heart cell death [2,4]. This damage leads to loss of the heart's muscle, which is made up of beating cells called "cardiomyocytes." The loss of cardiomyocytes decreases the heart's ability to pump blood throughout the body $[1,2,4]$. We used to believe that cardiomyocytes were not able to regenerate. However, it was recently discovered that cardiomyocytes do have some ability to regenerate [1]. While we are still learning about the regenerative capabilities of the human body, many organs, like the heart, are slow to heal which makes any damage to these organs difficult to treat. Transplantation is an option for replacing a damaged tissue or organ. However, there is a severe shortage of organs available for transplant. In Canada, about five patients die every week waiting for an organ transplant [5]. As an alternative to organ transplantation, regenerative medicine is showing promise as a therapy to repair the heart, and other slow healing organs, as shown in Figure 2. 
Figure 2

Regenerative medicine for the heart. As alternatives to heart transplant, regenerative therapies for the heart include cell therapy using adult stem cells (top left), biomaterials (top right), and pharmacological (medicines) interventions (bottom).

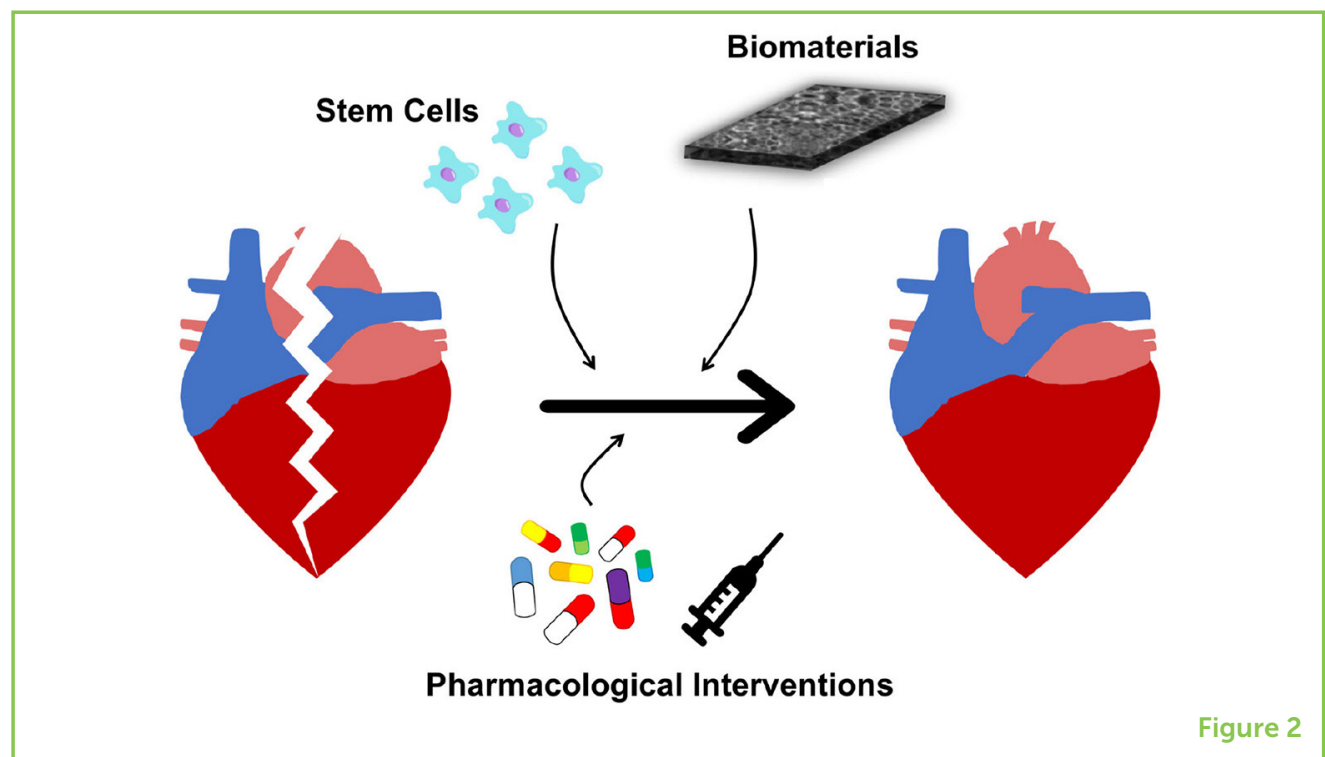

\section{BUT WAIT... ARE THERE ANY LIMITATIONS?}

Although biomaterials show a lot of promise, they are still a developing therapy; their full potential has yet to be explored. Some limitations of biomaterials have to do with how they interact with the patient's body. For example, while biomaterials are able to mimic the 3D environment of the organ or tissue they are repairing, the biomaterials are still different from the actual organ, and this can limit tissue regeneration. For example, biomaterials placed in the heart have to be able to contract with the beating heart, or they may cause irregular heartbeats [2]. Also, in the past, biomaterials have not allowed enough oxygen to flow through the heart to keep it healthy [2]. Last, up to now, biomaterials have only been able to repair an area about one quarter the size of the heart, so in the case of a large heart attack that damages more of the heart, they are not as useful $[1,2]$. As scientists continue to learn about the underlying causes of diseases, they will be able to develop new biomaterials to treat more diseases. In addition, biomaterials themselves are still advancing, which will hopefully lead to materials that can successfully treat a wide range of illnesses.

Other limitations of biomaterials are not so much physical but involve issues of the ethics (moral values and rules) and the laws around their use. There are ethical concerns about the type of materials used, and where they come from, for example, is it ethical to use materials taken from humans to make these materials?

Second, regulating biomaterials to make sure they are safe for patients can be difficult, because there is such a wide range of biomaterials, made of different components and used for different purposes. We 
need better ways to ensure that these new therapies are effective in regenerating damaged organs and tissues, in a way that does not harm the patient.

\section{CONCLUSION}

Significant progress has been made in the field of biomaterials and regenerative medicine, but there are still many advances that can be made. The next generation of scientists must continue to learn about and understand the interactions between the human body and biomaterials, in order to develop new, more effective therapies.

\section{ACKNOWLEDGMENTS}

EA and ES thank all the trainees who had worked in their labs who had been key for developing novel materials for organ repair and had also contributed to better understand the underlying cell-biomaterial interactions. The authors would also like to thank the support of the Canadian funding agencies NSERC (EA), CIHR (EA and ES), as well as to the University of Ottawa Heart Institute. CL thanks a Queen Elizabeth II scholarship for M.Sc. studies.

\section{REFERENCES}

1. Steinhauser, M. L., and Lee, R. T. 2011. Regeneration of the heart. EMBO Mol. Med. 3:701-12. doi: 10.1002/emmm.201100175

2. Chaudhuri, R., Ramachandran, M., Moharil, P., Harumalani, M., and Jaiswal, A. K. 2017. Biomaterials and cells for cardiac tissue engineering: current choices. Mater. Sci. Eng. C 79:950-7. doi: 10.1016/j.msec.2017.05.121

3. Bhat, S., and Kumar, A. 2013. Biomaterials and bioengineering tomorrow's healthcare. Biomatter 3:e24717. doi: 10.4161/biom.24717

4. Cannon, B. 2013. Cardiovascular disease: biochemistry to behaviour. Nature 493:S2-S3. doi: 10.1038/493S2a

5. Blood, Organ and Tissue Donation: Canada.ca (2018) [cited 2018 October 29, 2018]. Available online at: https://www.canada.ca/en/public-health/services/ healthy-living/blood-organ-tissue-donation.html\#a32

SUBMITTED: 11 October 2018; ACCEPTED: 16 January 2019; PUBLISHED ONLINE: 05 February 2019.

EDITED BY: Caroline Helen Brennan, Queen Mary University of London, United Kingdom 


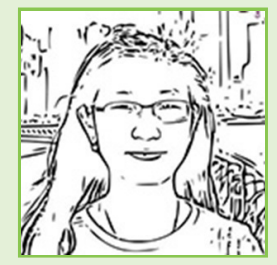

CITATION: Lazurko C, Harden S, Suuronen EJ and Alarcon El (2019) Biomaterials for Organ and Tissue Repair. Front. Young Minds 7:8. doi: 10.3389/ frym.2019.00008

CONFLICT OF INTEREST STATEMENT: The authors declare that the research was conducted in the absence of any commercial or financial relationships that could be construed as a potential conflict of interest.

COPYRIGHT @ 2019 Lazurko, Harden, Suuronen and Alarcon. This is an openaccess article distributed under the terms of the Creative Commons Attribution License (CC BY). The use, distribution or reproduction in other forums is permitted, provided the original author(s) and the copyright owner(s) are credited and that the original publication in this journal is cited, in accordance with accepted academic practice. No use, distribution or reproduction is permitted which does not comply with these terms.

\section{YOUNG REVIEWER}

\section{CAROLINE, AGE: 15}

I am a student and I like natural science. I have two older brothers who are working in science, particularly medicine so I am very interested in knowing more about medical sciences and health related topic. During my free time, I like to read books and eat good food.

\section{AUTHORS}

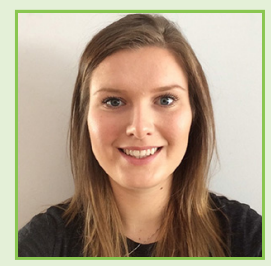

\section{CAITLIN LAZURKO}

I always have been interested in scientific research that has medical applications. I completed my honors B.Sc. in Biochemistry from the University of Ottawa in 2017. I worked on various projects, always applying basic science to clinical applications. Caitlin is currently pursuing an Master's Degree in Biochemistry at the University of Ottawa, with my research focusing on the development of new biomaterials as treatments for diabetic foot ulcers.

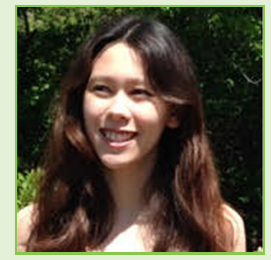

\section{SERENA HARDEN}

I am a high school student from Ottawa, Ontario. Outside of class, I enjoy conducting research in Biosciences. I have been working on developing a novel biomaterial for skin repair in diabetic foot ulcers. In my spare time, I like astronomy and playing the viola.

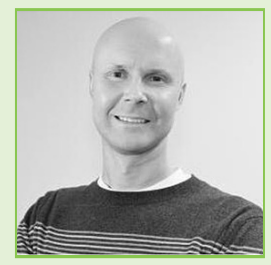

\section{ERIK J. SUURONEN}

I obtained my Ph.D. at the University of Ottawa studying how to get nerves to grow in artificial corneas. I now work at the University of Ottawa Heart Institute doing research to better understand cell-biomaterial interactions (www.beatsresearch.com). Outside of research, I enjoy spending time with my family or going on a run, and I really like the winter and cross-country skiing. *esuuronen@ottawaheart.ca 


\section{EMILIO I. ALARCON}

I am an Assistant Professor and Principal investigator at the University of Ottawa and University of Ottawa Heart Institute. My team focuses on developing novel biomaterials using nanoparticles as functional building blocks. Learn more about the exciting research at www.beatsresearch.com. *ealarcon@ottawaheart.ca 